\title{
Addition of Acknowledgement
}

In the March 2019 issue of Preventive Nutrition and Food Science (2019;24(1):32-40), a correction is necessary in the article "Long-Term Feeding of Soy Protein Attenuates Choline Deficient-Induced Adverse Effects in Wild Type Mice and Prohibitin 1 Deficient Mice Response More Sensitively" by Gieun Heo and Kwang Suk Ko.

On page 39, the acknowledgement was omitted from this article.

Additional acknowledgement is as follows;

\section{ACKNOWLEDGEMENTS}

This research is funded by The National Research Foundation of Korea \#2016R1D1A1B04935653.

The authors apologize to the readers for the error. 